\title{
Unregulated actin polymerization by WASp causes defects of mitosis and cytokinesis in X-linked neutropenia
}

\author{
Dale A. Moulding, ${ }^{1}$ Michael P. Blundell, ${ }^{1}$ David G. Spiller, ${ }^{3}$ \\ Michael R.H. White, ${ }^{3}$ Giles O. Cory, ${ }^{4}$ Yolanda Calle, ${ }^{5}$ Helena Kempski, ${ }^{2,6}$ \\ Jo Sinclair, ${ }^{1}$ Phil J. Ancliff, ${ }^{6,7}$ Christine Kinnon, ${ }^{1}$ Gareth E. Jones, ${ }^{5}$ \\ and Adrian J. Thrasher ${ }^{1,7}$
}

\author{
'Wolfson Centre for Gene Therapy of Childhood Disease and 2Molecular Haematology Unit, UCL Institute of Child Health, \\ University College London, London WC1N 1EH, UK \\ ${ }^{3}$ Centre for Cell Imaging, School of Biological Sciences, Bioscience Research Building, Liverpool L69 7ZB, UK \\ ${ }^{4}$ Department of Biochemistry, School of Medical Sciences, University of Bristol, Bristol BS8 1TD, UK \\ ${ }^{5}$ Randall Division of Cell \& Molecular Biophysics, King's College London, London SE1 1UL, UK \\ ${ }^{6}$ Department of Haematology and 'Department of Immunology, Great Ormond Street Hospital, London WC1N 3JH, UK
}

Specific mutations in the human gene encoding the Wiskott-Aldrich syndrome protein (WASp) that compromise normal auto-inhibition of WASp result in unregulated activation of the actin-related protein $2 / 3$ complex and increased actin polymerizing activity. These activating mutations are associated with an $\mathrm{X}$-linked form of neutropenia with an intrinsic failure of myelopoiesis and an increase in the incidence of cytogenetic abnormalities. To study the underlying mechanisms, active mutant WASp ${ }^{1294 T}$ was expressed by gene transfer. This caused enhanced and delocalized actin polymerization throughout the cell, decreased proliferation, and increased apoptosis. Cells became binucleated, suggesting a failure of cytokinesis, and micronuclei were formed, indicative of genomic instability. Live cell imaging demonstrated a delay in mitosis from prometaphase to anaphase and confirmed that multinucleation was a result of aborted cytokinesis. During mitosis, filamentous actin was abnormally localized around the spindle and chromosomes throughout their alignment and separation, and it accumulated within the cleavage furrow around the spindle midzone. These findings reveal a novel mechanism for inhibition of myelopoiesis through defective mitosis and cytokinesis due to hyperactivation and mislocalization of actin polymerization.

\section{CORRESPONDENCE}

Adrian J. Thrasher:

a.thrasher@ich.ucl.ac.uk

Abbreviations used: Arp2/3, actin-related protein $2 / 3$ complex; eGFP, enhanced GFP; ELA2, elastase 2; FISH, fluorescence in situ hybridization; GBD, GTPase binding domain; HPC, hematopoietic precursor cell; LCL, lymphoblastoid cell line; MOI, multiplicity of infection; SCN, severe congenital neutropenia; VCA, verprolin homology domain, central and acidic; WAS, Wiskott-Aldrich syndrome; WASp, WAS protein; XLN, X-linked neutropenia.
The Wiskott-Aldrich syndrome (WAS) protein (WASp) is a $502-$ amino acid member of a conserved family of proteins that participate in the dynamic regulation of actin polymerization primarily through activation of the actin-related protein 2/3 complex (Arp2/3) (1-3). WASp expression is restricted to hematopoietic cells (4) where it functions to integrate signals to control the restructuring of the actin cytoskeleton to facilitate cell locomotion, cell-cell interactions, and cell signaling essential for the regulated function of the immune system (for review see references 5 and 6). Interaction between the $\mathrm{C}$ terminal verprolin homology domain (VCA) of WASp (which consists of a verprolin homology domain, a central basic connecting region, and a

D.A. Moulding and M.P. Blundell contributed equally to this work.

The online version of this article contains supplemental material. terminal acidic region) and the Arp2/3 is essential for WASp-mediated actin nucleation, which is itself the rate limiting step in polymerization of monomeric G-actin (7-9). The activity of WASp is regulated by the adoption of an autoinhibited conformation in which the VCA domain forms a hydrophobic interaction with the central region of WASp (residues 230-310), spanning the GTPase binding domain (GBD; residues 230-288) (10, 11). Binding of GTPloaded Cdc42 and phosphatidylinositol 4,5bisphosphate appears to disrupt this interaction cooperatively, thereby freeing the $\mathrm{C}$ terminus for binding to the Arp2/3 (12-14). Other factors have also been shown to influence this process, for example phosphorylation of WASp on a single tyrosine residue (Y291) immediately adjacent to the GBD and within the VCA binding domain also leads to activation of WASp (15), and many 
SH3 domain-containing proteins (e.g., Nck, Grb2, Toca1, and WISH) also facilitate activation (for review see reference 6). Unfolding of the auto-inhibited WASp structure is the key step in WASp-mediated activation of the Arp2/3.

Defects in the WAS gene are most commonly associated with WAS and characterized by immunodeficiency, microthrombocytopenia, and eczema. WAS induces defects in multiple hematopoietic lineages, including $\mathrm{B}$ and $\mathrm{T}$ lymphocytes, natural killer cells, DCs, and platelets (for review see references 5 and 6). WAS patients also have an increased frequency of autoimmune disease and malignancies (16). There are around 300 distinct mutations reported in the WAS gene (for review see reference 5). Classical WAS has the most severe disease phenotype and occurs when WASp is absent or truncated, whereas X-linked thrombocytopenia is less severe and results from low levels of WASp expression (17). These related syndromes share the common feature that WASp activity is diminished or absent, leading to failure of cytoskeletal restructuring essential during an immune response (for review see references 5 and 6). In contrast to the loss of WASp activity underlying WAS and X-linked thrombocytopenia, three novel mutations (L270P [18], S272P, and I294T [19]) clustered within the GBD of WASp have recently been shown to result in enhanced actin-polymerizing activity and are found in patients with an X-linked form of severe congenital neutropenia (SCN; X-linked neutropenia [XLN]). The enhanced actin-polymerizing activity in the L270P mutant is due to disruption of the auto-inhibited conformation of WASp generating an unfolded protein that is constitutively active (18). The clustering of all three mutations within the GBD of WASp and the similarly enhanced actin-polymerizing activity suggest that all three mutations generate an auto-active protein. XLN has clinical characteristics, including recurrent bacterial infections, severe neutropenia, monocytopenia, low numbers of natural killer cells, and a skewed lymphocyte CD4/CD8 ratio $(18,19)$. Although there is strong genetic evidence linking activating mutations of WAS to XLN, a pathogenic mechanism has not been established.

We have previously shown that there are intrinsic defects of myelopoiesis in XLN with high levels of apoptosis in the bone marrow and variable acquired cytogenetic abnormalities (19). Retrospective fluorescence in situ hybridization (FISH) investigations for locus-specific changes revealed the discreet presence of tetraploid cells that were confirmed at the metaphase level. Tetraploidy can result from cell fusion, aborted mitosis, or failed cytokinesis (for review see reference 20). Cytokinesis is the final stage of cell division and requires the regulated assembly of a contractile ring of actin and myosin to cleave the cell in two (for review see reference 21). Gross disruption of actin dynamics by a variety of pharmacological agents leads to failure of cytokinesis resulting in tetraploid binucleate cells $(22,23)$. Subsequent division of tetraploid cells leads to a high frequency of aneuploidy and chromosomal rearrangements that are implicated in the progression of cancer $(24,25)$. Proliferation of tetraploid cells is thought to be prevented by a tetraploidy checkpoint that induces cell cycle arrest or apoptosis $(24,26)$.
We hypothesized that defective cytokinesis induced by deregulated actin polymerization may be the mechanism underlying XLN.

The actomyosin ring is highly dynamic with continuous assembly and disassembly of filamentous F-actin and in fission yeast depends on the Arp2/3, the formin Cdc12, profilin, and the WASp homologue WSP1 (27). In higher eukaryotes WASp and Arp2/3 have little direct role in the assembly and constriction of the actomyosin ring (21). However, wsp1 KO in Caenorhabditis elegans results in cytokinesis failure in one or more divisions in 5-10\% of embryos (28). We postulated that constitutively active mutant WASp could impede actomyosin ring function due to deregulated actin polymerization during the massive cellular restructuring involved in cell division. Forced expression of mutant WASp by gene transfer was therefore used to investigate causative mechanisms underlying XLN and to establish links between enhanced actin polymerization, inhibition of proliferation, and cytogenetic aberrations.

\section{RESULTS \\ Transgenic expression of WASp ${ }^{1294 \mathrm{~T}}$ results in enhanced actin-polymerizing activity}

We have previously identified a missense mutation, I294T, in a male child with XLN and variable tri-lineage bone marrow dysplasia (19). To study the mechanisms of disease, lentiviral vectors were constructed to express enhanced GFP (eGFP)-WASp and eGFP-WASp ${ }^{\mathrm{I} 294 \mathrm{~T}}$ in cell lines or primary cells. By Western blotting, eGFP-WASp and eGFP-WASp ${ }^{\text {I294T }}$ were detected as $\sim 90-\mathrm{kD}$ proteins in a representative human myeloid cell line, U937 (Fig. 1 A), and a nonhematopoietic human fibroblast cell line, HT1080 (Fig. 1 B). Endogenous WASp is restricted to the hematopoietic lineage and is detected as a $60-\mathrm{kD}$ protein in U937 (Fig. $1 \mathrm{~A}$ ), which is absent from HT1080 cells (Fig. 1 B). We observed a relative depletion of endogenous WASp when expressing increasing amounts of eGFP-WASp/eGFP-WASp ${ }^{\text {I294T }}$ in U937 cells, suggesting that there is tight regulation of the absolute levels of WASp in these cells (Fig. $1 \mathrm{~A}$ ).

XLN patient hematopoietic cells contain up to $50 \%$ more F-actin than normal control cells (19). Actin polymerization assays showed that the mutant WASp expressed in XLN patients had an enhanced ability to stimulate actin polymerization in cell-free assays $(18,19)$. To determine whether the in vitro activity of WASp ${ }^{\text {I294T }}$ caused increased actin polymerization within cells, U937 cells were transduced with eGFP, eGFP-WASp, and eGFP-WASp ${ }^{\text {I294T }}$. A dose-related elevation of F-actin was observed in cells transduced with eGFPWASp ${ }^{1294 T}$, whereas there was minimal change in controltransduced cells (Fig. 1 C). WASp is not grossly overexpressed in these transduced myeloid cells (Fig. 1 A), implying that the elevated levels of actin polymerization reflect increased specific activity. The increase in F-actin content induced by eGFP-WASp ${ }^{\text {I294T }}$ caused delocalized accumulation of F-actin throughout the cytoplasm. This was particularly clear in the adherent HT1080 cell line. F-actin was concentrated around the cell periphery in untransduced cells (Fig. 1 D, arrows) 

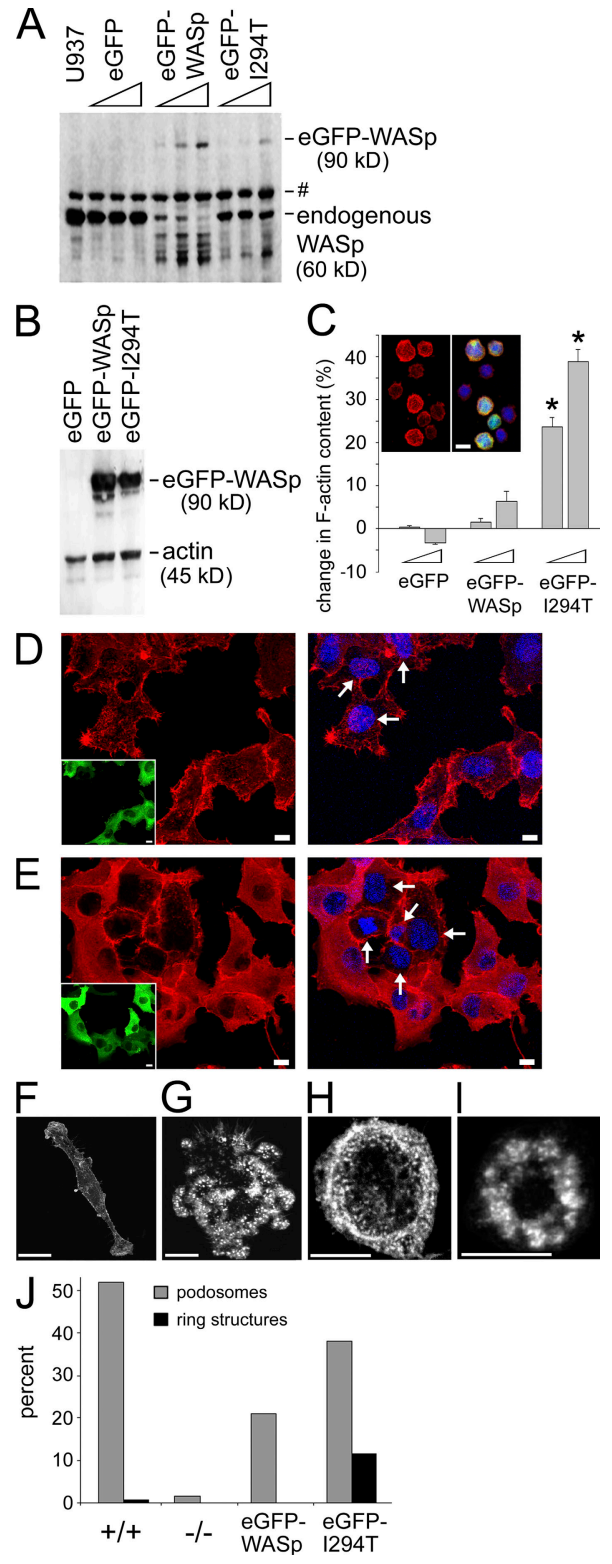

Figure 1. F-actin content is increased and delocalized by eGFPWASp ${ }^{1294 T}$. (A) eGFP-WASp and eGFP-WASp ${ }^{1244}$ expression in U937 cells. U937 cells were transduced with increasing amounts of lentivirus using an $\mathrm{MOI}$ of 5,10 , and 20 . Protein extracts were prepared $6 \mathrm{~d}$ after transduction. \#, an unidentified band detected at $\sim 66 \mathrm{kD}$. (B) eGFP-WASp and eGFP-WASp ${ }^{1294 T}$ expression in HT1080 cells. Extracts prepared $6 \mathrm{~d}$ after transduction at an $\mathrm{MOI}$ of 10. (C) F-actin levels (determined by flow cytometry) in U937 cells transduced at an $\mathrm{MOI}$ of 1 and 5 . Inset shows F-actin- (red), eGFP-WASp ${ }^{1294 T}$-, and DAPI-stained nuclei (blue). ${ }^{*}$, P $<0.003$ compared with eGFP-transduced cells. (D and E) F-actin in HT1080 cells transduced with eGFP-WASp (D) and eGFP-WASp ${ }^{1294 T}$ (E). Panels show F-actin (red, phalloidin), DNA (blue, DAPI), and eGFP-WASp/WASp ${ }^{1294 T}$ (inset), with arrows indicating untransduced cells. (F) Bac1 macrophages do not normally assemble podosomes (phalloidin staining). ( $\mathrm{G}$ and $\mathrm{H}$ ) Multiple podosomes are formed in eGFP-WASp ${ }^{1294 T}$-transduced Bac1 macrophages (G), occasionally in ring structures (H). (I) Podosome ring structure in WAS KO mouse DCs transduced with eGFP-WASp ${ }^{1294 T}$. (J) Percentage of mouse DCs with podosomes or podosome ring structures and was not altered by expression of eGFP (not depicted) or eGFP-WASp (Fig. 1 D). In contrast, F-actin was present throughout the cytoplasm in eGFP-WASp ${ }^{\text {I294T }}$-transduced cells (Fig. 1 E).

Functionality of eGFP-WASp fusion proteins was confirmed by their ability to rescue podosome formation. Bac1 macrophages do not normally assemble podosomes (Fig. 1 F). Expression of eGFP-WASp or eGFP-WASp ${ }^{\text {I294T }}$ restored podosome formation in Bac1 cells. Podosomes in eGFPWASp ${ }^{\text {I294T }}$-transduced Bac1 cells were often in multiple clusters (Fig. $1 \mathrm{G}$ ) and sometimes in large, densely packed rings (Fig. $1 \mathrm{H}$ ) reminiscent of primary macrophages derived from XLN patients (19). The nature of podosomes was confirmed by the colocalization of eGFP-WASp ${ }^{\text {I294T }}$ and vinculin to podosome structures (not depicted). Rescue of podosome formation was also achieved in mouse WAS KO DCs by expression of eGFP-WASp and eGFP-WASp ${ }^{\text {I294T }}$ (Fig. $1 \mathrm{~J}$ ). As noted previously, eGFP-WASp ${ }^{\text {I294T }}$ caused formation of densely packed rings of podosomes (Fig. 1, I and J). In summary, eGFP-WASp ${ }^{\text {I294T }}$ promoted exaggerated actin-polymerizing activity in a variety of cell types and mimics the phenotype seen in WASp ${ }^{1294 T}$ patient cells.

\section{eGFP-WASp ${ }^{1294 T}$ inhibits proliferation and increases apoptosis}

Proliferation of myeloid cells in culture was severely compromised in primary WASp ${ }^{\mathrm{I} 294 \mathrm{~T}}$ patient progenitors, suggesting that there is an intrinsic restriction (19). To characterize the mechanisms underlying the lack of proliferation, U937 cell cultures transduced with eGFP, eGFP-WASp, and eGFPWASp $^{\text {I294T }}$ were analyzed over a 17-d period. eGFP-WASp ${ }^{\text {I294T }}$ expression decreased the proliferation of these cells, as untransduced cells in the same culture outgrew the eGFP-WASp ${ }^{1294 T}-$ expressing cells, resulting in a reduction in the percentage of eGFP-WASp ${ }^{\text {I294T }}$ cells over time (Fig. 2 A). This diminished proliferation was not a spurious result of lentiviral transduction, as neither eGFP nor eGFP-WASp exhibited this effect (Fig. 2 A). In conjunction with the slower growth of the eGFP-

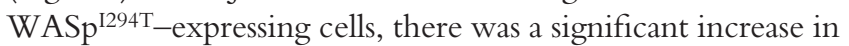
apoptosis (Fig. 2, B and C). The inhibition of proliferation and induction of apoptosis caused by eGFP-WASp ${ }^{\text {I294T }}$ was confirmed in HT1080 fibroblasts, a nonhematopoietic cell line that does not normally express WASp (Fig. S1, A and B, available at http://www.jem.org/cgi/content/full/jem.20062324/DC1). These results establish a direct link between expression of autoactive WASp and the reduced proliferation and increased apoptosis seen in XLN.

\section{WASp ${ }^{1294 T}$ causes tetraploidy and other cytogenetic abnormalities}

Cytogenetic analysis of bone marrow samples from the index patient revealed loss of chromosome 13 in 3/16 metaphase

in untransduced WT $(+\mid+)$, WAS KO $(-\mid-)$, and WAS KO transduced with eGFP-WASp or eGFP-WASp ${ }^{1294 T}$. Bar, $10 \mu \mathrm{m}$. 


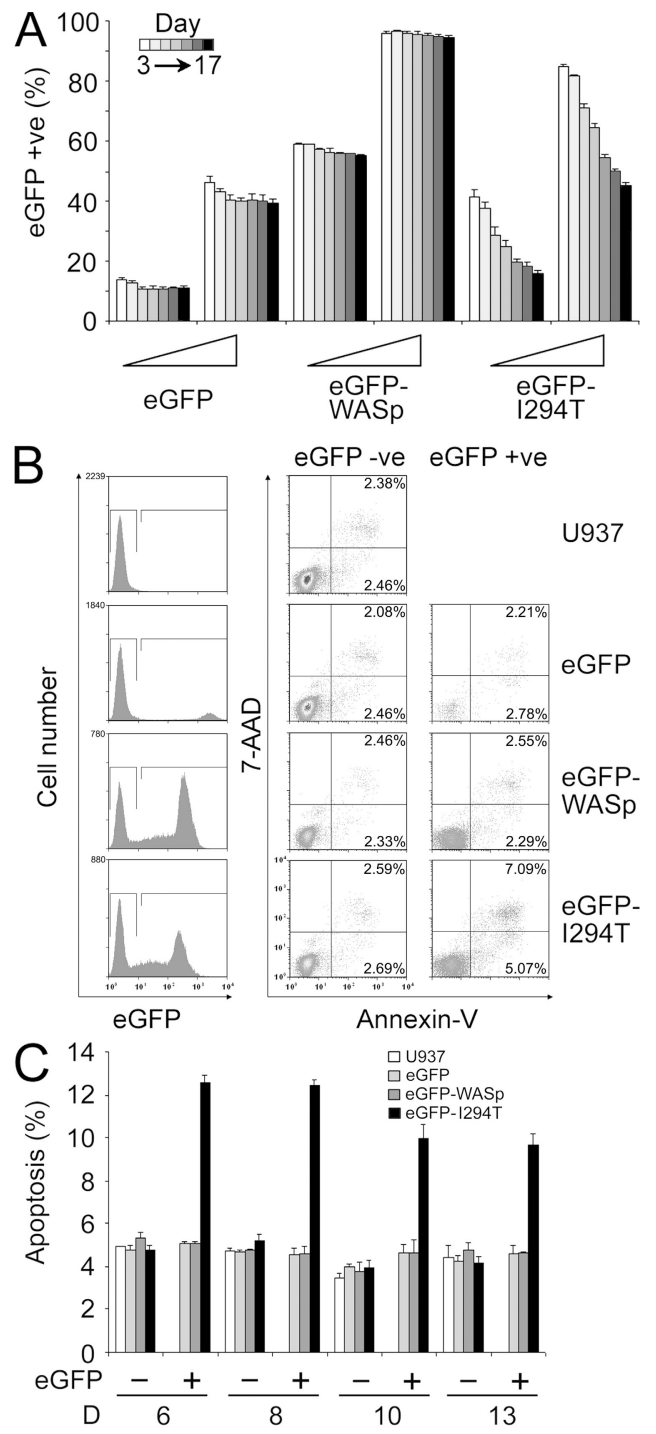

Figure 2. eGFP-WASp ${ }^{1294 \mathrm{~T}}$ expression retards proliferation and induces apoptosis. (A) U937 cells transduced with eGFP ( $\mathrm{MOl}$ of 0.2 and 1), eGFP-WASp (MOI of 1 and 5), or eGFP-WASp ${ }^{1294 T}$ (MOI of 1 and 5) were analyzed for eGFP expression by flow cytometry $3,6,8,10,13,15$, and $17 \mathrm{~d}$ after transduction (each bar represents the mean \pm SD value of the percentage of eGFP+ cells in the culture for independent triplicates from each day). (B) Apoptosis assessed by flow cytometry (annexin $V$ and 7AAD staining) $8 \mathrm{~d}$ after transduction at the lower MOls shown in A. (C) Apoptosis (annexin $\mathrm{V}^{+}$) quantified in triplicate samples 6, 8, 10, and $13 \mathrm{~d}$ after transduction at the lower MOls shown in $\mathrm{A}$. ${ }^{*}, \mathrm{P}<0.005$ compared with untransduced U937 cells in the same culture. eGFP was transduced at a lower MOI than other constructs, as eGFP expression was 5-10-fold higher than all other eGFP fusion proteins.

cells, one of which also had monosomy 14 (19). Retrospective FISH investigations for locus-specific changes revealed the discreet presence of tetraploid cells that were confirmed at the metaphase level. The generation of cytogenetic abnormalities was further investigated in a WASp ${ }^{\mathrm{I} 294 \mathrm{~T}} \mathrm{~B}$ lymphoblastoid cell line (LCL; derived from patient peripheral blood). Cytogenetic analysis was performed by locus-specific identifier-FISH using probes for $R B 1$ (chromosome 13), BCR (chromosome $22)$, and the chromosome $7 \alpha$-satellite region and locus D7S486 (Fig. 3, A-D, and Tables I and II). The WASp ${ }^{\text {I294T B-LCL }}$ population displayed a variety of cytogenetic abnormalities, including tetraploidy (Fig. 3 B), amplification of RB1 (Fig. 3 C), and loss of one copy of RB1 (Fig. 3 D). Analysis of metaphase cells showed there was a significant increase in both tetraploidy and amplification of RB1 (Table I). A significant proportion of interphase WASp ${ }^{\mathrm{I} 294 \mathrm{~T}} \mathrm{~B}-\mathrm{LCLs}$ also appeared to be tetraploid, as they exhibited tetrasomy for both RB1 and BCR (Table I). Interphase WASp ${ }^{\text {I294T }}$ cells also showed a greater frequency of cells that had lost or gained copies of RB1 without changes in BCR copy number (Table I). Similar rates of cytogenetic abnormalities were seen using the D7S486 probe (Table II). The frequency of asynchronous replication (where one allele has replicated and the other has not, generating a characteristic singlet/doublet hybridization signal) was similar in both WASp ${ }^{\text {I294T }}$ B-LCLs and control B-LCLs (Tables I and II). In summary WASp ${ }^{1294 \mathrm{~T}}$ is associated with a substantial increase in cytogenetic abnormalities, with tetraploidy being the most common defect observed.

\section{eGFP-WASp ${ }^{1294 T}$ induces increased DNA content and nuclear abnormalities}

The DNA content of transduced U937 cells expressing eGFP or eGFP-WASp remained similar to that of untransduced cells. In contrast, the percentage of cells with a DNA content of $>4 \mathrm{n}$ was significantly increased in cells expressing eGFPWASp $^{\text {I294T }}$ (Fig. 3 E). This assay may underestimate the number of tetraploid cells in culture, as tetraploid cells have a DNA content of $4 n$ when in $G_{0 / 1}$ and only have a DNA content $>4 \mathrm{n}$ when they enter the cell cycle. We therefore stained cells histochemically and visualized them by light microscopy. In cultures of U937 cells expressing eGFPWASp ${ }^{1294 T}$, there was striking nuclear heterogeneity with frequent multinucleated cells (Fig. 3, F and G). The frequency of cells with micronuclei (a marker of genomic instability resulting form abnormal mitosis and cytokinesis) (29, 30) was significantly increased by eGFP-WASP ${ }^{\mathrm{I} 294 \mathrm{~T}}$ (Fig. 3, F and G, dashed arrows). Asymmetric division of tetraploid cells was also observed in eGFP-WASp ${ }^{\text {I294T }}$-transduced cells (Fig. 3 G, white arrow). The induction of these nuclear abnormalities was confirmed in the nonhematopoietic HT1080 cell line (Fig. S1, C-F). Cytogenetic studies of eGFP-WASp ${ }^{\text {I294T_ }}$ transduced HT1080 cells using the chromosome $7 \alpha$-satellite region and locus D7S486 probe also revealed higher frequencies of tetraploid cells both at interphase and metaphase (unpublished data). These results show that auto-active WASp can induce multinucleation and cytogenetic abnormalities in transformed cell lines. To confirm that auto-active WASp was able to induce multinucleation in the primary cells targeted in XLN, human $\mathrm{CD} 4^{+}$hematopoietic precursor cells (HPCs) were transduced with eGFP,eGFP-WASp, and eGFP-WASp ${ }^{\text {I294T }}$. Transduced HPCs were analyzed after growth in myeloid conditions for 7 and $10 \mathrm{~d}$ (Fig. 3, H and I). eGFP and eGFPWASp control cultures showed $\sim 1 \%$ of cells with two nuclei, 

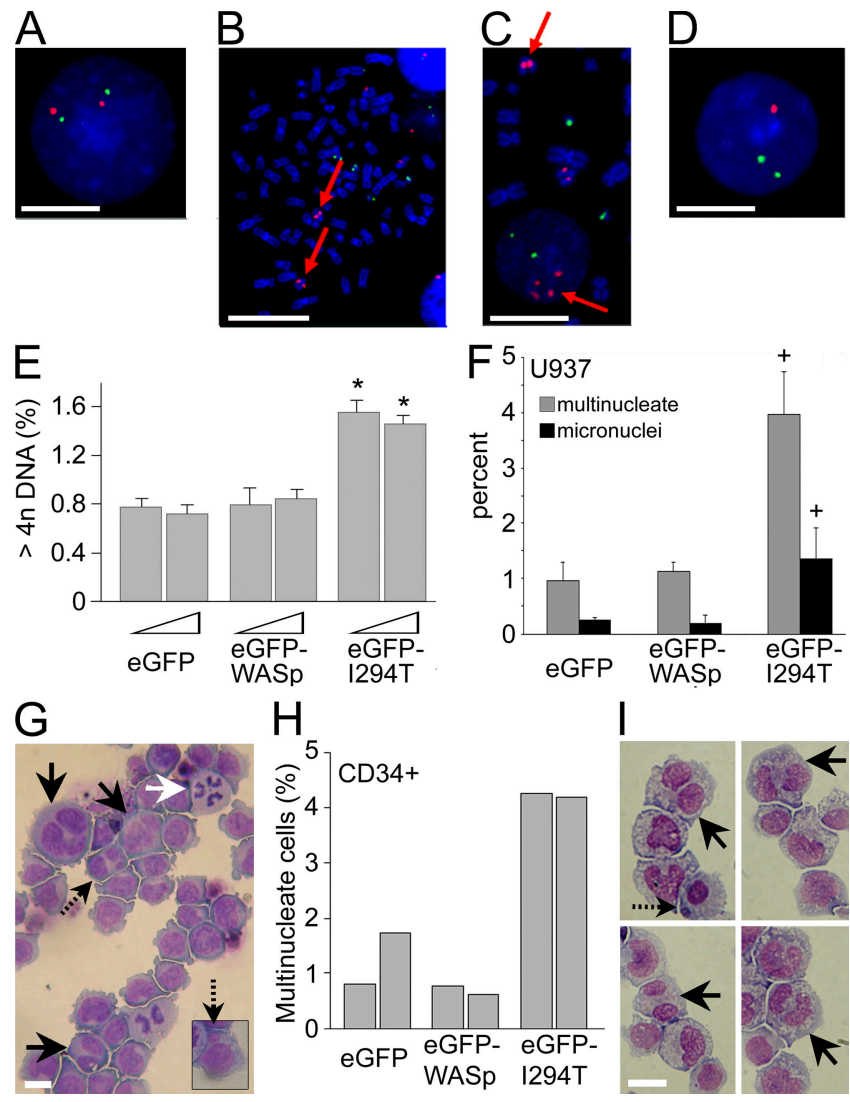

Figure 3. WASp ${ }^{1294 \mathrm{~T}}$ induces cytogenetic abnormalities in patientderived B-LCLs, transduced cell lines, and primary HPCs. (A) Normal interphase cell showing two copies of RB1 (red signals) and two copies of the control probe $B C R$ (green signals). (B) Metaphase tetraploid cell showing four copies of $R B 1$ (two of which are amplified; arrows indicate the two chromosomes with increased signal intensity) and four copies of $B C R$. (C) Partial metaphase cell and adjoining interphase cell. Amplification of $R B 1$ is seen on one of the two copies of chromosome 13 (arrowed, increased signal intensity) and also confirmed in the interphase cell by four copies of the $R B 1$ (arrowed) compared with two copies of the control probe, $B C R$. (D) Abnormal interphase cell showing loss of one copy of $R B 1$. (E) eGFP-WASp ${ }^{1294 T}$-expressing U937 cells (from Fig. 2 A; MOI of 5) show increased DNA content assessed by flow cytometry of independent triplicates propidium iodide stained $13 \mathrm{~d}$ after transduction. (F) Percentage of U937 cells on cytospins with multiple nuclei (gray bars) and micronuclei (black bars). Data is the average from days 3, 7, 10, and 14. (G) Images of cytospins from U937 (eGFP-WASp ${ }^{1294 T}$; MOI of 5, day 6). Cells showed multiple nuclei (black arrows), micronuclei (dashed arrows), and asymmetric three-way division (white arrow). (H) Percentage multinucleate human primary CD34+ cells on cytospins (days 7 and $10 ; n=1$ ). (I) CD $34^{+}$ HPCs show binucleation when expressing eGFP-WASp ${ }^{1294 T}$. ${ }^{*}, P<0.001$; ,$+ P<0.01$ compared with eGFP, eGFP-WASp, or untransduced U937 cells. Bars: $B, G$, and $I, 20 \mu \mathrm{m} ; A, C$, and $D, 10 \mu \mathrm{m}$.

whereas this was increased to $\sim 4 \%$ in cell cultures expressing eGFP-WASp ${ }^{\text {I294T }}$. Auto-active WASp therefore causes nuclear abnormalities in both cell lines and primary cells. Collectively, the findings of cytogenetic abnormalities associated with polyploidy are suggestive of a substantial disturbance of mitosis and cytokinesis.
Pharmacologically increased F-actin levels cause binucleation and apoptosis

The nuclear abnormalities and apoptosis induced by autoactive WASp were associated with increased and delocalized F-actin. Jasplakinolide is a fungal toxin that stabilizes F-actin and increases the rate of actin nucleation resulting in the disordered assembly of branched F-actin networks (31, 32). U937 cells were cultured for $48 \mathrm{~h}$ with jasplakinolide, and multinucleation, apoptosis, and actin localization were analyzed. Jasplakinolide caused the generation of multinucleate cells in a dose- and time-dependent manner (Fig. 4, A and B). Micronuclei were also formed in many cells after exposure to jasplakinolide (Fig. 4 B). The dose-dependent formation of multinucleated cells was accompanied by increased levels of apoptosis (Fig. 4 C). The stabilization and delocalization of F-actin by jasplakinolide in U937 cells was confirmed by confocal microscopy. F-actin was labeled with anti- $\beta$-actin antibody according to a protocol that specifically labels filamentous actin (33), as phalloidin staining was inhibited by jasplakinolide (31). F-actin in untreated U937 cells was concentrated around the cell cortex (Fig. 4 D). 24-h incubation with jasplakinolide caused the formation of dense F-actin aggregates, as reported previously (32), as well as a moderate increase in F-actin throughout the cytoplasm (Fig. 4 D). Therefore, pharmacological stabilization and delocalization of F-actin produce very similar aberrations to those observed with auto-active WASp, suggesting that these events are directly linked.

\section{eGFP-WASp ${ }^{1294 T}$ delays completion of mitosis and causes cytokinesis failure}

To investigate the development of nuclear abnormalities, we imaged cell division in multiple fields in unsynchronized U937 cell cultures by confocal microscopy. Cultures contained an equal proportion of transduced and untransduced cells. Mitosis was measured by staining DNA and timing from DNA condensation in prometaphase past furrow ingression to DNA decondensation in telophase (Fig. $5 \mathrm{~A}$ ). In this typical example, the nucleus is relatively large before mitosis ( $-4 \mathrm{~min})$, has visibly condensed in prometaphase ( $0 \mathrm{~min})$, followed by chromosomal alignment in metaphase $(16 \mathrm{~min})$, and separation of chromosomes in anaphase (44 min) accompanied by the beginning of furrow ingression (Fig. 5 A, top panel). DNA starts to decondense, and furrow ingression appears complete (54 min) with DNA decondensation appearing complete at $65 \mathrm{~min}$. Completion of cytokinesis was confirmed when the two daughter cells had visibly moved away from one another (160 min). The duration of mitosis was timed in U937 transduced with eGFP-WASp or eGFP-WASp ${ }^{\text {I294T }}$ and compared with control untransduced cells in the same cultures. The duration of mitosis in U937 cells expressing eGFP-WASp ${ }^{\text {2294T }}$ was significantly longer than untransduced controls (Fig. 5 C). Mitosis lasted $56.5 \pm 13.3$ min in untransduced cells, whereas cells expressing eGFP-WASp ${ }^{\text {I294T }}$ took $87.7 \pm 44.6 \mathrm{~min}$. Only 3 of 24 untransduced cells took longer than "normal" to complete mitosis, whereas 17 of 34 cells expressing eGFP-WASp ${ }^{\text {I294T }}$ showed an extended duration of mitosis. The delay in progression through mitosis 
Table I. FISH analysis for the RB1 and BCR loci

\begin{tabular}{|c|c|c|c|c|c|}
\hline Metaphase & Normal ploidy & Tetraploidy & Amplification of $R B 1$ & $\begin{array}{c}\text { Loss of one } R B 1 \\
\text { signal }\end{array}$ & \\
\hline 1294TWASp LCL & $92.0(69 / 75)$ & $5.4^{*}(4 / 75)$ & $2.6^{*}(2 / 75)$ & $0.0(0 / 75)$ & \\
\hline Control LCL 1 & 100.0 & 0.0 & 0.0 & 0.0 & \\
\hline Control LCL 2 & 100.0 & 0.0 & 0.0 & 0.0 & \\
\hline Control PBL & 100.0 & 0.0 & 0.0 & 0.0 & \\
\hline Interphase & Normal & Tetrasomy RB1 \& BCR & Tetrasomy RB1 & $\begin{array}{l}\text { Loss of one RB1 } \\
\text { signal }\end{array}$ & $\begin{array}{l}\text { Asynchronous } \\
\text { replication } \\
\text { of RB1 }\end{array}$ \\
\hline${ }^{1294 T W A S p ~ L C L}$ & $82.7(286 / 346)$ & $6.6^{*}(23 / 346)$ & $3.2^{*}(11 / 346)$ & $3.5(12 / 346)$ & $4.0(14 / 346)$ \\
\hline Control LCL 1 & 94.6 & 0.0 & 0.0 & 0.0 & 5.4 \\
\hline Control LCL 2 & 93.6 & 1.3 & 0.0 & 1.3 & 3.8 \\
\hline Control PBL & 98.3 & 0.0 & 0.0 & 0.0 & 1.7 \\
\hline
\end{tabular}

Comparison of the frequency (\%) of cells displaying abnormal hybridization patterns for the $R B 1$ and $\mathrm{BCR}$ loci in LCLs and peripheral blood lymphocytes (PBL). ${ }^{*}, \mathrm{P}<0.002$ when compared with the control LCLs.

in eGFP-WASp ${ }^{\text {I294T }}$ U937 cells always occurred between prometaphase and anaphase, as shown in the typical example in Fig. 5 B. eGFP-WASp transduced cells showed no difference from untransduced control cells, demonstrating a specific effect of eGFP-WASp ${ }^{\text {I294T }}$ in prolonging mitosis (Fig. 5 C). The nonhematopoietic HT1080 cell line had a similar delay in mitosis when expressing eGFP-WASp ${ }^{\text {I294T }}$ (Fig. S2, available at http://www.jem.org/cgi/content/full/jem.20062324/DC1).

The live cell imaging experiments shown in Fig. 5 (A-C) did not allow long-term tracking of individual cells after division, as there was considerable movement of the nonadherent U937 cells. A second set of imaging experiments was performed in semisolid (methocult) culture to partially restrict cell movement and allow the fate of cells to be tracked over a 27-h period. The inclusion of methocult did not completely prevent movement of U937 cells, so some movement in and out of the field of view still occurred. 248 untransduced and 240 eGFP-WASp ${ }^{\text {I294T }}$-transduced U937 cells were imaged in seven fields of view, with 87 untransduced and 91 transduced cells completing mitosis without moving out of the field of view.
Untransduced U937 cells successfully completed cytokinesis in

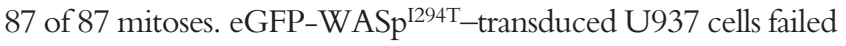
to complete cytokinesis in 11 of 91 mitoses, significantly more frequently than controls (Fig. $5 \mathrm{E} ; \mathrm{P}=0.0007$, Fisher's exact test). A typical example of failed cytokinesis is shown in Fig. 5 D. Furrow ingression was completed in a near to normal time in 10 of the 11 failed cytokinetic events, whereas furrow ingression was not initiated in the remaining instance of cytokinesis failure. Furrow regression typically occurred 15-35 min after furrow ingression and almost always within $60 \mathrm{~min}$ (with a single exception shown in Fig. S3, available at http://www .jem.org/cgi/content/full/jem.20062324/DC1). Cytokinesis generating three daughter cells occurred in 2 of 91 eGFP$\mathrm{WASp}^{\mathrm{I} 294 \mathrm{~T}}$ mitoses, in both cases from a binucleated parent cell (Fig. S3 shows an example).

The long-term imaging of U937 cultures allowed investigation of any relationship between delayed mitosis, failed cytokinesis, and apoptosis (Fig. 5 F). Apoptosis followed failed cytokinesis in 4 of the 11 instances, with apoptosis initiated $85,105,230$, and $580 \mathrm{~min}$ after the completion of

Table II. Fish analysis for the D7S486 and BCR loci

\begin{tabular}{|c|c|c|c|c|}
\hline Metaphase & Normal ploidy & Tetraploidy & Loss of one chr.7 allele & \\
\hline 1294TWASp LCL & $91.8(45 / 49)$ & $8.2(4 / 49)$ & $0.0(0 / 49)$ & \\
\hline Control LCL 1 & 100.0 & 0.0 & 0.0 & \\
\hline Control LCL 2 & 100.0 & 0.0 & 0.0 & \\
\hline Control PBL & 100.0 & 0.0 & 0.0 & \\
\hline Interphase & Normal & Tetrasomy D7S486 \& BCR & Loss of one chr.7 allele & $\begin{array}{c}\text { Asynchronous } \\
\text { replication of } \\
\text { chr.7 }\end{array}$ \\
\hline I294TWASp LCL & $92.0(368 / 400)$ & $4.25+(17 / 400)$ & $1.5(6 / 400)$ & $2.25(9 / 400)$ \\
\hline Control LCL 1 & 97.9 & 1.2 & 0.0 & 0.9 \\
\hline Control LCL 2 & 96.3 & 1.9 & 0.9 & 0.9 \\
\hline Control PBL & 98.0 & 0.0 & 1.0 & 1.0 \\
\hline
\end{tabular}

Comparison of the frequency (\%) of cells displaying abnormal hybridization patterns for chromosome 7 and BCR in LCLs and peripheral blood lymphocytes (PBL).

+ , significance $(P<0.05)$ when compared with the control LCLs. 

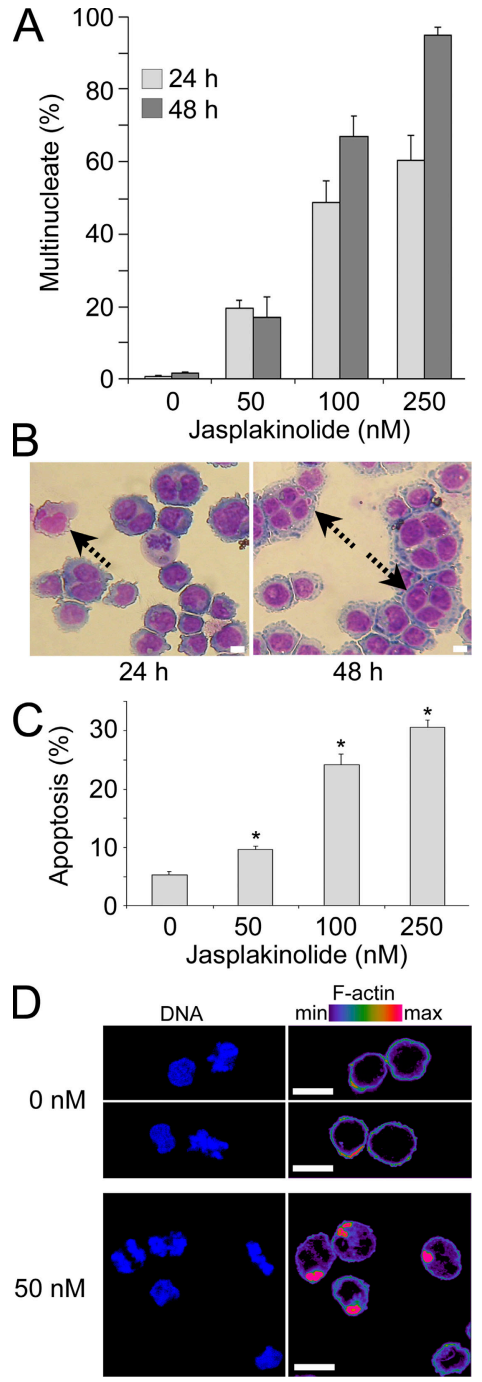

Figure 4. Jasplakinolide causes multinucleation and apoptosis. (A) The percentage of multinucleate U937 from cytospins after culture for 24 and $48 \mathrm{~h}$ in media alone or supplemented with 50,100, and $250 \mathrm{nM}$ jasplakinolide (mean \pm SD of triplicates, $>400$ cells per cytospin). (B) Images from cytospins with micronucleated cells highlighted. (C) Apoptosis (annexin $\mathrm{V}^{+}$) after $24 \mathrm{~h}$ of culture (mean $\pm \mathrm{SD}$ of triplicates). (D) F-actin (antibody stained, see Materials and methods) in U937 after $24 \mathrm{~h}$ of culture with and without $50 \mathrm{nM}$ jasplakinolide. Bar, $10 \mu \mathrm{m}$.

nuclear division (Fig. S3 shows an example). The remaining seven cells that failed cytokinesis survived until the end of the experiment (or they moved out of the field of view) 1,2, 5, $8,11,12$, and $23 \mathrm{~h}$ after mitosis. There was a striking correlation between abnormal cytokinesis and delayed mitosis (Fig. $5 \mathrm{~F})$. The duration of mitosis in cells that had a failed or abnormal cytokinesis (Fig. 5 F, black, green, and blue circles) was significantly longer than the mitosis in cells that had a successful cytokinesis (Fig. 5 F, open circles). The increased level of apoptosis induced by eGFP-WASp ${ }^{\mathrm{I} 294 \mathrm{~T}}$ (Fig. 2, B and C) was largely due to death of binucleated cells (Fig. 5 G). Apoptosis of untransduced U937 cells imaged for $27 \mathrm{~h}$ was $<2 \%$. In contrast, apoptosis levels in U937 expressing eGFP-
WASp ${ }^{\mathrm{I} 94 \mathrm{~T}}$ in the same culture was $8 \%$. The increase in apoptosis was due to death of cells that were binucleated (so had failed cytokinesis) or had an extended duration of mitosis (Fig. 5 G). The expression of eGFP-WASp ${ }^{\text {I294T }}$ therefore causes a delayed completion of mitosis that is associated with a subsequent failure of cytokinesis, followed by apoptosis of the resulting binucleated cells.

\section{eGFP-WASp ${ }^{1294 T}$ causes abnormal F-actin accumulation} around mitotic chromosomes and in the cleavage furrow

The increased and delocalized F-actin induced by auto-active WASp (Fig. 1, C-E) was measured in cell populations that were predominately in interphase. eGFP-WASp ${ }^{\text {294T }}$ was excluded from the nucleus, and F-actin was present throughout the cytoplasm in cells expressing auto-active WASp (Fig. 1 E). Live cell imaging revealed that eGFP-WASp (not depicted) and eGFP$\mathrm{WASp}^{\mathrm{I} 294 \mathrm{~T}}$ transiently entered the nuclear area during mitosis before being excluded from the nucleus during telophase, presumably coincident with breakdown and reformation of the nuclear membrane (Fig. 6 A). Confocal microscopy of fixed HT1080 cells confirmed this relocalization of eGFP-WASp (Fig. $6 \mathrm{~B}$ and Fig. S4, which is available at http://www.jem.org/ cgi/content/full/jem.20062324/DC1) and eGFP-WASp ${ }^{\text {I294T }}$ (Fig. $6 \mathrm{C}$ and Fig. S4) during mitosis. Both wild-type and mutant eGFP-WASp surrounded condensed chromosomes during prometaphase, metaphase, and anaphase. However, only the movement of auto-active (Fig. 6 C), not wild-type (Fig. 6 B), WASp during mitosis was accompanied by an accumulation of F-actin around the mitotic chromosomes. Pseudo-colored images revealed that $\mathrm{F}$-actin permeates the entire nuclear area in cells expressing auto-active WASp, surrounding chromosomes in prometaphase and metaphase. The mitotic spindle is not grossly perturbed by eGFP-WASp ${ }^{\text {I294T }}$, despite the abnormal presence of $\mathrm{F}$-actin around the mitotic spindle and between the spindle poles and chromosomes.

During anaphase, delocalized F-actin was concentrated in the cytoplasm in the center of the cleavage furrow around the spindle midzone in cells expressing eGFP-WASp ${ }^{\mathrm{I} 294 \mathrm{~T}}$ (Fig. 6 C), but not when expressing eGFP-WASp (Fig. 6 B). Despite the abundance of delocalized cytoplasmic F-actin, a contractile ring was still able to form in the cleavage furrow in cells expressing eGFP-WASp ${ }^{1294 T}$, and bundling of microtubules into a condensed spindle midzone also occurred. F-actin fibers remained in the reforming nuclei in telophase in the eGFP-WASp ${ }^{\text {I294T }}$ cells, even when the eGFP-WASp ${ }^{\text {I294T }}$ had returned to its interphase localization in the cytoplasm (Fig. 6 C). In summary, the increased and delocalized F-actin induced by auto-active WASp during interphase persists during all stages of mitosis surrounding condensed chromosomes and the mitotic spindle, and accumulating around the spindle midzone during furrow ingression.

\section{DISCUSSION}

SCN is often associated with mutations in the elastase 2 (ELA2) gene, but a considerable proportion are triggered by unknown mechanisms (34). The ELA2 gene product, the 

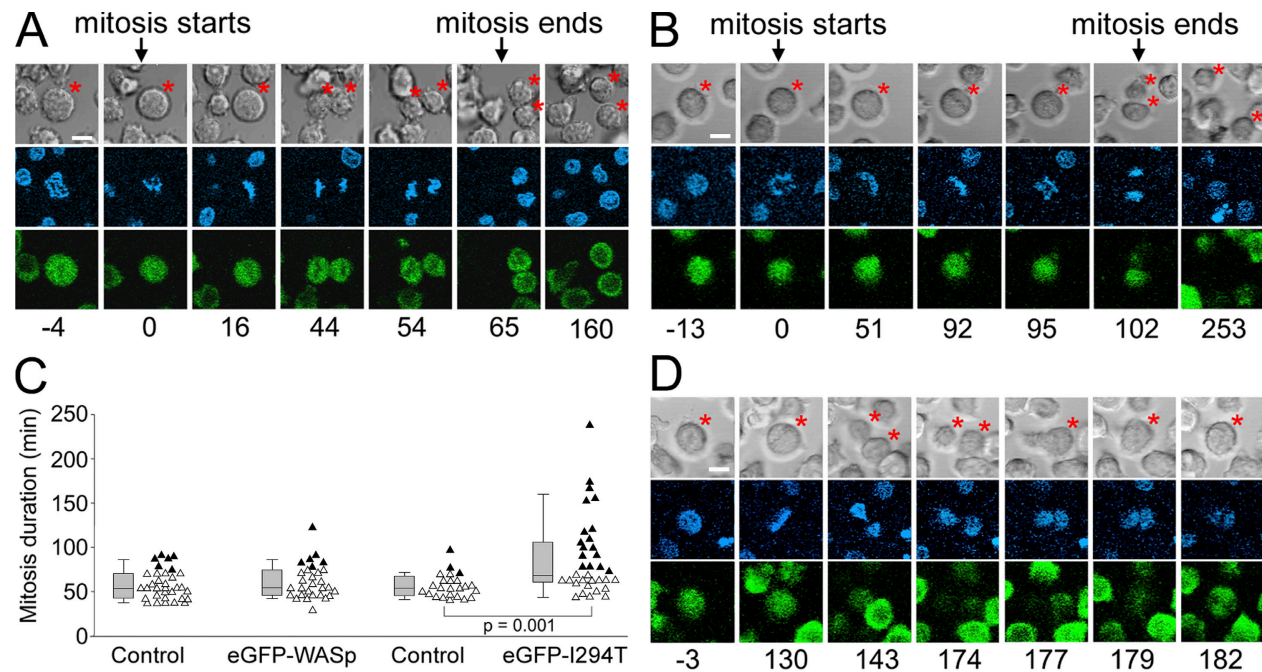

$D^{-13}$
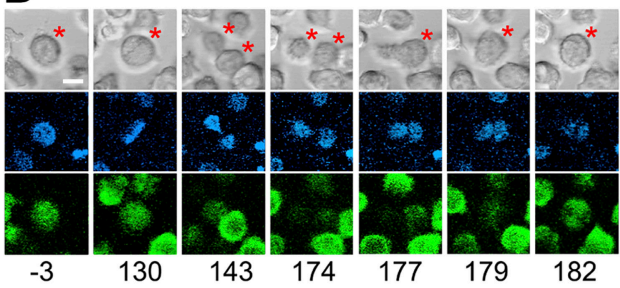

$\mathrm{E}$

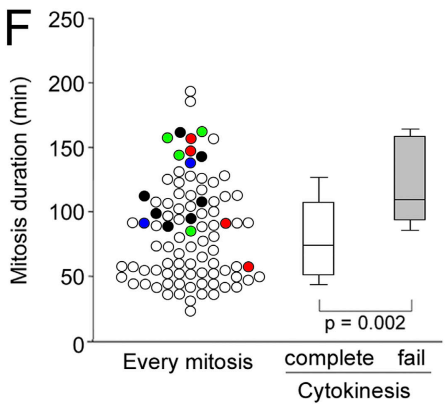

- Cytokinesis fails Cytokinesis fails then apoptosis

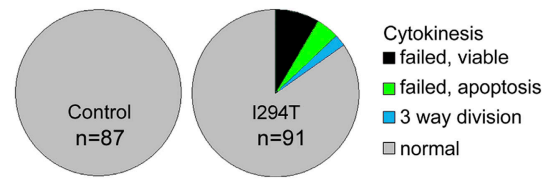

$\bullet$ 3-way division

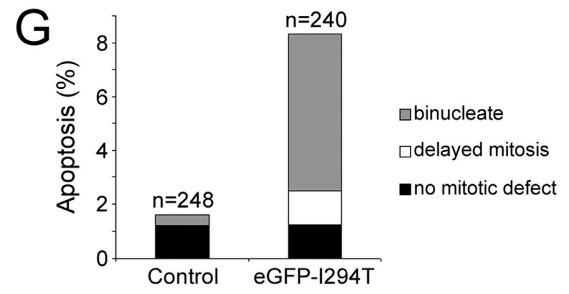

Figure 5. eGFP-WASp ${ }^{1294 T}$ expression delays completion of mitosis and causes cytokinesis failure. (A) Mitosis and cytokinesis proceed normally in a typical U937 cell expressing eGFP-WASp, with this representative example (red asterisk) showing division into two daughter cells. Top panels show the U937 cells, middle panels show DNA (blue), and bottom panels show eGFP. (B) Delayed mitosis in a typical U937 cell expressing eGFP-WASpl294T. (C) U937 cells expressing eGFP-WASp ${ }^{1294}$, but not eGFP-WASp, have a delay in completing mitosis. Black points denote cells whose division took longer than normal (with "normal" being outside the mean \pm SD for control cell division). Gray boxes show 25-75th percentile, the horizontal line is the median, and lines above and below are the 90th and 10th percentile. (D) An example of delayed mitosis and failed cytokinesis in an eGFP-WASp ${ }^{1294 T}$ U937 cell. (E) Frequency of abnormal cytokinesis was quantified by time-lapse live cell confocal microscopy over a 27-h culture period. (F) 91 mitoses of eGFP-WASp ${ }^{1294 T}$ U937 cells showing time for completion of mitosis and cell fate (open circles denote successful cytokinesis). Boxes show the duration of mitosis of cells that completed (white box) and failed (gray box) cytokinesis. (G) Cells that became apoptotic during time-lapse confocal microscopy during $27 \mathrm{~h}$ of culture were separated between binucleate cells, cells that had an extended mitosis (>70 min), or normal cells that were mononuclear and had no delay in mitosis. Bar, $10 \mu \mathrm{m}$.

protease elastase, is expressed in neutrophils and monocytes and participates in the killing of ingested microbes. Although there is strong genetic evidence linking mutations of ELA2 to $\mathrm{SCN}$, the mechanisms underlying neutropenia remain controversial and range from a direct cellular toxicity to induction of the unfolded protein response $(34,35)$. Recently, autosomal recessive congenital neutropenia has been linked with a deficiency of HAX1, a protein critical in maintaining mitochondrial membrane potential and protecting against apoptosis in myeloid cells (36). Three novel mutations (L270P, S272P, and I294T) in the WAS gene have been linked with an X-linked form of SCN, termed XLN $(18,19)$.
Although the known toxicity of elastase provides an attractive theory for a mechanism of neutropenia, the activation of WASp is not so obviously linked to cell death. In this study, we have shown that auto-active WASp causes an increase in, and delocalization of, F-actin; decreased proliferation; increased apoptosis; cytogenetic abnormalities, most notably tetraploidy; a delay in mitosis; and failure of cytokinesis.

A failure of cytokinesis results in tetraploidy, with tetraploid cells activating a tetraploidy checkpoint that arrests cells in $G_{1}$ or triggers apoptosis $(24,26)$. The relative frequency of these two fates of tetraploid cells is unknown (21). The risks of checkpoint escape or mitotic slippage could clearly lead to 


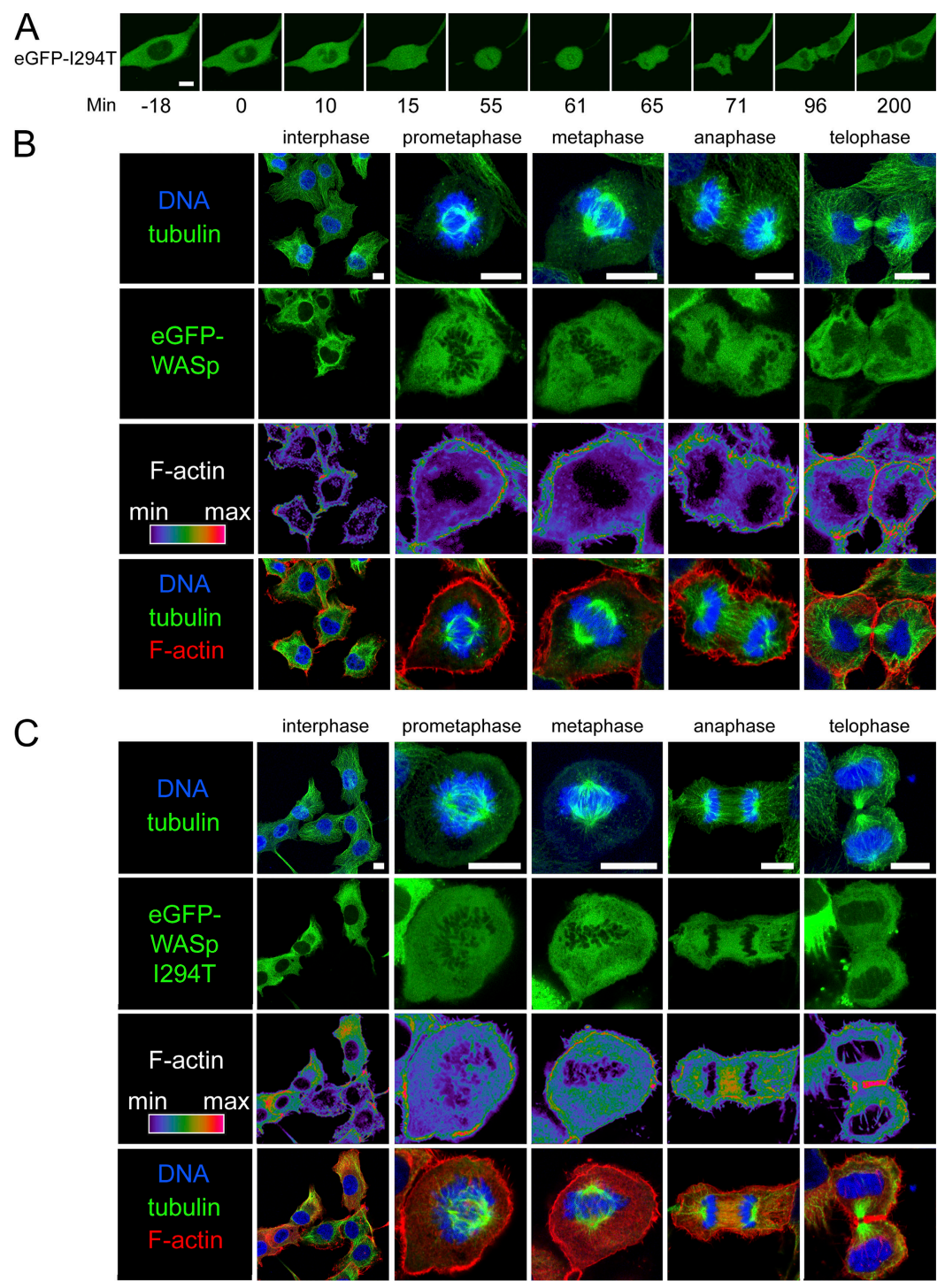

Figure 6. Abnormal F-actin localization during mitosis in cells expressing eGFP-WASp ${ }^{1294 T}$. (A) Live cell imaging of eGFP-WASp $294 \mathrm{~T}$ during mitosis in a HT1080 cell. (B and C) Fixed cell confocal microscopy of representative HT1080 cells expressing eGFP-WASp (B) and eGFP-WASpl294T (C) during interphase, prometaphase, metaphase, anaphase, and telophase. Stages of mitosis were identified by DNA and tubulin localization (top panels, maximal projection of entire cell). Remaining panels show a $\sim 1-\mu m$ slice through the center of the cell's DNA. F-actin was pseudo-colored to highlight abundance and localization through the cell. Bar, $10 \mu \mathrm{m}$.

polyploidy, aneuploidy, and genomic instability (for review see reference 20). The trigger for activation of the tetraploidy checkpoint is not fully resolved and may be independent of the tetraploid state of the cell (37) and be triggered by actin and microtubule disruption during interphase before these cytoskeletal defects induce tetraploidy $(38,39)$. The tetraploid checkpoint has also been shown to require previous activation of the spindle assembly checkpoint during mitosis (40). Cell cycle arrest and apoptosis of tetraploid cells can be triggered by p53-dependent and -independent pathways, adding further complexity to this system (26). Similar mechanisms exist to remove cells containing micronuclei that arise from lagging chromosomes in mitosis (29). The expression of auto-active WASp is likely to trigger the tetraploidy checkpoint potently, as it causes cytoskeletal disruption, mitotic delay, and tetraploidy. The disturbances of cell division induced by autoactive WASp therefore provide a mechanism explaining the tetraploidy and micronucleation seen in XLN, which then lead to growth arrest and apoptosis. This provides a novel causative link between a genetic mutation and SCN.

WASp is expressed in all hematopoietic cells, yet lymphocyte numbers are normal in XLN. Auto-active WASp clearly influences cell division in these cells, as there is induction of tetraploidy in immortalized B cell lines from WASp ${ }^{\text {294T }}$ peripheral blood. Stimulation of WASp ${ }^{\mathrm{I} 294 \mathrm{~T}}$ peripheral blood T lymphocytes with PHA also leads to the generation of tetraploid cells (unpublished data). This raises the question of why only cells of the myeloid lineage are lacking in XLN. 
A clue toward an explanation for this apparent discrepancy comes from a study using VX-680, a small molecule inhibitor of the aurora kinases involved in mitosis and cytokinesis (for review see reference 41). VX-680 has been shown to suppress tumor growth in vivo through inhibition of cell cycle and induction of apoptosis (42). There are striking parallels between auto-active WASp-induced XLN and VX-680 treatment, including defective cytokinesis, the generation of polyploid cells, and the development of reversible neutropenia in an animal model. It therefore appears that the myeloid lineage is particularly sensitive to defects of cell division, likely as a result of the continual high turnover and production of these cells.

The exact mechanism(s) by which auto-active WASp leads to a delay in mitosis and a failure of cytokinesis is not known. In fission yeast it is believed that the actomyosin ring plays an important role in spindle orientation. Pharmacological inhibition of actin polymerization results in activation of a mitotic checkpoint that ensures mitotic spindles are correctly orientated before anaphase is allowed to take place (43). A similar mechanism may exist in human cells by which forced and unregulated actin polymerization compromises actomyosin ring formation and delays the completion of mitosis. Cytokinesis requires massive cellular restructuring and coordinated cytoskeletal rearrangement. It is therefore likely that deregulated WASp activity could compromise cytokinesis either directly by disturbing normal actomyosin ring formation or indirectly by depletion or sequestration of critical substrates for actin polymerization in delocalized cytoskeletal structures. Similar arguments relating to the formation of an actomyosin constricting ring could be made for WASpdeficient cells, and although abnormalities of cytokinesis have not been described, WAS patients are particularly susceptible to lymphoreticular malignancy.

The abundance of delocalized F-actin triggered by autoactive WASp is likely to produce a direct physical inhibition of mitosis and cytokinesis. eGFP-WASp ${ }^{\text {I294T }}$ is expressed in the cytoplasm and excluded from the nucleus in interphase cells, but the breakdown of the nuclear envelope during mitosis allows eGFP-WASp ${ }^{\text {I294T }}$ to localize throughout the cell, which in turn triggers F-actin assembly around the mitotic chromosomes. This F-actin network may provide a physical barrier to inhibit chromosome capture and separation by spindle microtubules. The presence of F-actin throughout the cytoplasm may similarly physically impede cytokinesis by preventing abscission of daughter cells due to F-actin traversing the cytoplasmic bridge left after actomyosin ring closure. Alternatively, the excessive F-actin present in the cytoplasm surrounding the spindle midzone during late anaphase may interfere with the signaling from the spindle midzone to the cell cortex that is essential for furrowing and cytokinesis.

Excessive polymerization of $\mathrm{F}$-actin may provide a novel mechanism for cell death and genomic instability in other acquired disease states. Expression of a constitutively active form of Cdc42 (which is a direct activator of WASp and NWASp) in pulmonary artery endothelial cells has been shown to cause polyploidy and genomic instability (44). However, the same effect occurred when cells expressed active Rac, strongly supporting the suggestion that unregulated activation of the actin cytoskeleton per se, even through different pathways, is sufficient to induce the same mitotic and cytokinetic disturbances. Further study of the disturbances of mitosis and cytokinesis by auto-active WASp could provide valuable insight into these processes.

\section{MATERIALS AND METHODS}

Reagents and plasmids. All reagents were from Sigma-Aldrich unless otherwise stated. Antibodies against $\beta$-tubulin, $\beta$-actin, and vinculin were from Sigma-Aldrich; WASp was from Santa Cruz Biotechnology, Inc. and BD Biosciences; and goat anti-mouse IgG-Cy5 was from Jackson ImmunoResearch Laboratories. Rhodamine-phalloidin, DAPI, mounting solution (prolong gold antifade reagent), and jasplakinolide were from Invitrogen. Annexin V and 7AAD were from BD Biosciences.

Cell culture. HT1080 fibrosarcoma cells were cultured in DMEM supplemented with $10 \%$ FCS, $100 \mathrm{IU} / \mathrm{ml}$ penicillin, and $100 \mu \mathrm{g} / \mathrm{ml}$ streptomycin; Bac1 macrophages in DMEM supplemented with $10 \%$ FCS, $30 \mathrm{ng} / \mathrm{ml}$ M-CSF, $100 \mathrm{IU} / \mathrm{ml}$ penicillin, and $100 \mu \mathrm{g} / \mathrm{ml}$ streptomycin; and U937 and B-LCL in RPMI 1640 supplemented with $10 \%$ FCS, $100 \mathrm{IU} / \mathrm{ml}$ penicillin, and $100 \mu \mathrm{g} / \mathrm{ml}$ streptomycin. CD $34^{+}$human HPCs were isolated from G-CSF mobilized peripheral blood (derived from normal donors according to institutional protocols and local ethical approvals) using CliniMACS columns (Miltenyi Biotec) and cultured in IMDM supplemented with 20\% FCS, 100 $\mathrm{ng} / \mathrm{ml} \mathrm{SCF}, 100 \mathrm{ng} / \mathrm{ml}$ Flt3 ligand, $20 \mathrm{ng} / \mathrm{ml}$ IL-3, and $20 \mathrm{ng} / \mathrm{ml} \mathrm{IL-6}$ with lentivirus added and left for 24 h. $10^{5}-2 \times 10^{5}$ cells were then seeded into 24-well plates in IMDM supplemented with $20 \%$ FCS, $100 \mathrm{ng} / \mathrm{ml} \mathrm{G-CSF}$, $20 \mathrm{ng} / \mathrm{ml} \mathrm{SCF}$, and $20 \mathrm{ng} / \mathrm{ml} \mathrm{IL}-3$ to generate myeloid cells. Mouse DCs were prepared by plating $10^{7}$ bone marrow cells at a density of $10^{6} / \mathrm{ml}$ in RPMI 1640 containing 10\% FCS and $20 \mathrm{ng} / \mathrm{ml} \mathrm{GM-CSF}$. Media was replaced every $3 \mathrm{~d}$, and nonadherent cells were removed. On day 7 , adherent DCs were analyzed for CD11c expression and were 80-90\% CD11 $\mathrm{c}^{+}$.

Lentiviral production and transduction. Lentiviral vectors expressing eGFP, eGFP fused to human WASp, and eGFP fused to human WASp with the I294T mutation were prepared in the pHR'SIN-cPPT-CE and pHR'SIN-cPPT-SE lentiviral backbones as described previously (45). Virus was titred by transducing HT1080 cells and measuring transduction efficiency by the percentage of cells with eGFP fluorescence. Experiments with HT1080 used the CMV promoter to drive expression of eGFP and eGFPWASp fusions. All other cell types used the spleen focus forming virus promoter. Cells were transduced at a multiplicity of infection (MOI) ranging from 0.2 to 20 (U937, HT1080, and Bac1 cell lines). Human CD34+ cells were transduced at an MOI of 100, resulting in transduction of $\sim 30 \%$ of the population.

Western blotting. Protein lysates were separated on 4-12\% NuPage gels (Invitrogen) transferred to PVDF membranes and probed with antibodies using standard techniques. WASp was detected with Santa Cruz Biotechnology, Inc. anti-WASp clone B9 (concurrently with anti-actin antibody from SigmaAldrich) in HT1080 lysates and with BD Biosciences anti-WASp in U937 lysates. Horseradish peroxidase-conjugated secondary antibody (GE Healthcare) was detected using supersignal west pico substrate (Pierce Chemical Co.) and an Uvichemi documentation system (Uvitech).

Flow cytometry. Phalloidin staining of U937s was achieved by fixing cells in $4 \%$ paraformaldehyde (Polysciences Inc.) in PBS and permeabilization with Perm/Wash (BD Biosciences). Rhodamine-phalloidin was added at $2.5 \mu \mathrm{l}$ per $100 \mu \mathrm{l}$ and incubated for $30 \mathrm{~min}$. After washing in Perm/Wash, cells were analyzed by flow cytometry. The difference in phalloidin staining between $\mathrm{GFP}^{+}$and $\mathrm{GFP}^{-}$cells in the same sample was calculated using Summit 
v4.1 software (DakoCytomation). GFP fluorescence analysis was performed after fixation in $4 \%$ paraformaldehyde for $30 \mathrm{~min}$ at room temperature in the dark. Apoptosis was assessed by annexin V-PE and 7AAD staining according to standard protocols (BD Biosciences). DNA content was assessed by staining with propidium iodide by hypotonic lysis as described previously (46).

Cytogenetic studies. Bone marrow cells and EBV-immortalized B-LCLs were prepared for FISH analysis by conventional cytogenetic procedures. The probes selected for investigation were chosen for confirmation and further characterization of the karyotypic abnormalities observed in the diagnostic samples from the patient $45, \mathrm{XY},-7[1 / 20]$ in the initial diagnostic sample and from $45, \mathrm{XY},-13[2 / 16] / 44, \mathrm{XY},-13,-14[1 / 16]$ in a follow-up sample $6 \mathrm{mo}$ later (19). Slides were pretreated in $2 \times \mathrm{SSC}$ at $37^{\circ} \mathrm{C}$ for $1 \mathrm{~h}$, dehydrated through a series of ethanol washes, and denatured in $70 \%$ formamide, $2 \times \mathrm{SSC}$ for $2 \mathrm{~min}$. Locus-specific identifier probes for the RB1 and BCR genes, and a dual-color probe for the chromosome $7 \alpha$-satellite region and locus D7S486 (maps to 7q31), were prepared and hybridized according to the manufacturer's instructions (Abbott Laboratories). Cells were viewed using a CCD camera (Photometrics) connected to a Macintosh Quadra computer. Image analysis was effected using SmartCapture software (Digital Scientific). 30-75 metaphase cells were examined for abnormalities of chromosomes 7 and 13, and between 100 and 400 interphase cells were analyzed for each probe set used.

Fixed cell microscopy. Cytospins were prepared using a Shandon II cytocentrifuge. After air drying, cells were stained with Diff-Quick (Medion Diagnostics) and analyzed under a $20 \times$ objective. 10 random fields (totaling $>1,000$ cells for U937 and >150 cells for CD34) were counted from each slide. For confocal microscopy, cells were grown on 13-mm glass coverslips and mitotic cells were fixed and stained as described previously (47). Staining of interphase cells omitted the glycine incubation. Rhodamine-phalloidin was used at $1 \mu \mathrm{l}$ per $100 \mu \mathrm{l}$ for $20 \mathrm{~min}$, DAPI at $1 \mu \mathrm{M}$ for $5 \mathrm{~min}$. F-actin detection by anti-actin antibody was as described previously (33), a protocol that gives staining indistinguishable from phalloidin. Coverslips were mounted and analyzed on a Leica SPS2 confocal microscope. A single optical section or maximal projections from 6 to $10 \mathrm{Z}$-stacks were exported to Adobe Photoshop for final image preparation.

Live cell microscopy. Cells were transduced 7 to $14 \mathrm{~d}$ before analysis. Transduction at MOIs between 1 and 5 were used to achieve expression of eGFP-WASp and eGFP-WASp ${ }^{\mathrm{I} 294 \mathrm{~T}}$ at similar levels per cell and in $\sim 50 \%$ of the population (MFI of $\mathrm{eGFP}^{+}$cells measured by flow cytometry were near identical for eGFP-WASp and eGFP-WASp ${ }^{\text {I294T }}$, ranging from 151 to 260 and 151 to 235, respectively). Time-lapse live cell imaging was performed on a Ziess LSM510 NLO META (equipped with incubator XL running at $37^{\circ} \mathrm{C}$ and $5 \% \mathrm{CO} 2$, an automated stage, and a $40 \times$ plan-NEOFLUAR objective) using the autotimeseries Macro with autofocus (48). Cell nuclei were stained with Hoechst 33258 at a final concentration of $10 \mu \mathrm{g} / \mathrm{ml}$, and fluorescence was excited with a Coherent titanium sapphire Mira 900 laser tuned to $765 \mathrm{~nm}$ (which was fiber-optically coupled to the scan head via a Coherent GDC), whereas emitted light was detected from a 545-nm dichroic mirror through a $685-\mathrm{nm}$ short-pass filter. eGFP fluorescence (either expressed alone or as a fusion protein) was excited with the 488-nm line of an argon ion laser, and emitted light was detected through a 490-nm longpass and a 500-550 band-pass filter. Fluorescent and transmission images of each field of cells in a glass-bottom 35-mm Petri dish (Iwaki supplied by Steralin) were collected every $2-5 \mathrm{~min}$ for periods up to $2 \mathrm{~d}$. The minimum amount of light was used to excite fluorescence while retaining a clear image. U937 cell medium was supplemented with a third of MethoCult H4100 (StemCell Technologies Inc.) to restrict cell movement due to convection currents in the medium.

Statistical analysis. Bar graphs are presented as mean, with error bars indicating standard deviation. Two-sample equal variance (homoscedastic) $t$ tests were performed using Microsoft Excel, assuming a two-tailed distribution. Division time plots used SigmaPlot to show the median, $10^{\text {th }}, 25^{\text {th }}, 75^{\text {th }}$, and $90^{\text {th }}$ percentile.
Online supplemental material. In Fig. S1, eGFP-WASp ${ }^{\mathrm{I} 294 \mathrm{~T}}$ slows proliferation, induces apoptosis, and causes multinucleation in HT1080 fibroblasts. In Fig. S2, eGFP-WASp ${ }^{\mathrm{I} 244 \mathrm{~T}}$ delays the completion of mitosis in HT1080 fibroblasts. Fig. S3 shows cytokinesis failure and apoptosis inU937 cells expressing eGFP-WASp ${ }^{\text {I294T }}$. Fig. S4 shows tubulin, F-actin, DNA, and eGFP localization during mitosis in HT1080 transduced with eGFP, eGFPWASp, and eGFP-WASp ${ }^{\text {I294T }}$. The online supplemental material is available at http://www.jem.org/cgi/content/full/jem.20062324/DC1.

This work has been supported by grants from the Wellcome Trust (to D.A. Moulding, Y. Calle, J. Sinclair, G.E. Jones, A.J. Thrasher, D.G. Spiller, and M.R.H. White); the European Union (to M.P. Blundell and A.J. Thrasher; Policy-oriented and harmonizing research activities in the field of primary immunodeficiency diseases, SP23-CT-2005-006411); the Roald Dahl Foundation, Amgen (unrestricted educational grant), and REACH (to P.J. Ancliff); the Department of Trade and Industry and the Biotechnology and Biological Sciences Research Council (to D.G. Spiller and M.R.H. White); and the Leukaemia Research Fund (H. Kempski).

The authors have no conflicting financial interests.

Submitted: 3 November 2006

Accepted: 24 July 2007

\section{REFERENCES}

1. Machesky, L.M., and R.H. Insall. 1998. Scar1 and the related WiskottAldrich syndrome protein, WASP, regulate the actin cytoskeleton through the Arp2/3 complex. Curr. Biol. 8:1347-1356.

2. Marchand, J.B., D.A. Kaiser, T.D. Pollard, and H.N. Higgs. 2001. Interaction of WASP/Scar proteins with actin and vertebrate Arp2/3 complex. Nat. Cell Biol. 3:76-82.

3. Zalevsky, J., L. Lempert, H. Kranitz, and R.D. Mullins. 2001. Different WASP family proteins stimulate different Arp $2 / 3$ complex-dependent actin-nucleating activities. Curr. Biol. 11:1903-1913.

4. Derry, J.M., H.D. Ochs, and U. Francke. 1994. Isolation of a novel gene mutated in Wiskott-Aldrich syndrome. Cell. 78:635-644.

5. Burns, S., G.O. Cory, W. Vainchenker, and A.J. Thrasher. 2004. Mechanisms of WASp-mediated hematologic and immunologic disease. Blood. 104:3454-3462.

6. Ochs, H.D., and A.J. Thrasher. 2006. The Wiskott-Aldrich syndrome. J. Allergy Clin. Immunol. 117:725-738.

7. Higgs, H.N., and T.D. Pollard. 1999. Regulation of actin polymerization by Arp2/3 complex and WASp/Scar proteins. J. Biol. Chem. 274:32531-32534.

8. Yarar, D., W. To, A. Abo, and M.D. Welch. 1999. The WiskottAldrich syndrome protein directs actin-based motility by stimulating actin nucleation with the Arp2/3 complex. Curr. Biol. 9:555-558.

9. Le Clainche, C., D. Didry, M.F. Carlier, and D. Pantaloni. 2001. Activation of Arp2/3 complex by Wiskott-Aldrich Syndrome protein is linked to enhanced binding of ATP to Arp2. J. Biol. Chem. 276:46689-46692.

10. Rudolph, M.G., P. Bayer, A. Abo, J. Kuhlmann, I.R. Vetter, and A. Wittinghofer. 1998. The Cdc42/Rac interactive binding region motif of the Wiskott Aldrich syndrome protein (WASP) is necessary but not sufficient for tight binding to $\mathrm{Cdc} 42$ and structure formation. J. Biol. Chem. 273:18067-18076.

11. Kim, A.S., L.T. Kakalis, N. Abdul-Manan, G.A. Liu, and M.K. Rosen. 2000. Autoinhibition and activation mechanisms of the Wiskott-Aldrich syndrome protein. Nature. 404:151-158.

12. Prehoda, K.E., J.A. Scott, R.D. Mullins, and W.A. Lim. 2000. Integration of multiple signals through cooperative regulation of the N-WASP-Arp2/3 complex. Science. 290:801-806.

13. Rohatgi, R., H.Y. Ho, and M.W. Kirschner. 2000. Mechanism of N-WASP activation by CDC42 and phosphatidylinositol 4, 5-bisphosphate. J. Cell Biol. 150:1299-1310.

14. Higgs, H.N., and T.D. Pollard. 2000. Activation by Cdc42 and PIP(2) of Wiskott-Aldrich syndrome protein (WASp) stimulates actin nucleation by Arp2/3 complex. J. Cell Biol. 150:1311-1320.

15. Cory, G.O., R. Garg, R. Cramer, and A.J. Ridley. 2002. Phosphorylation of tyrosine 291 enhances the ability of WASp to stimulate actin polymerization and filopodium formation. Wiskott-Aldrich Syndrome protein. J. Biol. Chem. 277:45115-45121. 
16. Sullivan, K.E., C.A. Mullen, R.M. Blaese, and J.A. Winkelstein. 1994. A multiinstitutional survey of the Wiskott-Aldrich syndrome. J. Pediatr. $125: 876-885$.

17. Lutskiy, M.I., F.S. Rosen, and E. Remold-O’Donnell. 2005. Genotypeproteotype linkage in the Wiskott-Aldrich syndrome. J. Immunol. 175:1329-1336.

18. Devriendt, K., A.S. Kim, G. Mathijs, S.G. Frints, M. Schwartz, J.J. Van Den Oord, G.E. Verhoef, M.A. Boogaerts, J.P. Fryns, D. You, et al 2001. Constitutively activating mutation in WASP causes X-linked severe congenital neutropenia. Nat. Genet. 27:313-317.

19. Ancliff, P.J., M.P. Blundell, G.O. Cory, Y. Calle, A. Worth, H. Kempski, S. Burns, G.E. Jones, J. Sinclair, C. Kinnon, et al. 2006. Two novel activating mutations in the Wiskott-Aldrich syndrome protein result in congenital neutropenia. Blood. 108:2182-2189.

20. Storchova, Z., and D. Pellman. 2004. From polyploidy to aneuploidy, genome instability and cancer. Nat. Rev. Mol. Cell Biol. 5:45-54.

21. Glotzer, M. 2005. The molecular requirements for cytokinesis. Science. 307:1735-1739.

22. Martineau, S.N., P.R. Andreassen, and R.L. Margolis. 1995. Delay of HeLa cell cleavage into interphase using dihydrocytochalasin B: retention of a postmitotic spindle and telophase disc correlates with synchronous cleavage recovery. J. Cell Biol. 131:191-205.

23. Senderowicz, A.M., G. Kaur, E. Sainz, C. Laing, W.D. Inman, J. Rodriguez, P. Crews, L. Malspeis, M.R. Grever, E.A. Sausville, and K.L.K. Duncan. 1995. Jasplakinolide's inhibition of the growth of prostate carcinoma cells in vitro with disruption of the actin cytoskeleton. J. Natl. Cancer Inst. 87:46-51.

24. Andreassen, P.R., O.D. Lohez, F.B. Lacroix, and R.L. Margolis. 2001. Tetraploid state induces p53-dependent arrest of nontransformed mammalian cells in G1. Mol. Biol. Cell. 12:1315-1328.

25. Fujiwara, T., M. Bandi, M. Nitta, E.V. Ivanova, R.T. Bronson, and D. Pellman. 2005. Cytokinesis failure generating tetraploids promotes tumorigenesis in p53-null cells. Nature. 437:1043-1047.

26. Castedo, M., A. Coquelle, S. Vivet, I. Vitale, A. Kauffmann, P Dessen, M.O. Pequignot, N. Casares, A. Valent, S. Mouhamad, et al. 2006. Apoptosis regulation in tetraploid cancer cells. EMBO J. 25:2584-2595.

27. Pelham, R.J., and F. Chang. 2002. Actin dynamics in the contractile ring during cytokinesis in fission yeast. Nature. 419:82-86.

28. Withee, J., B. Galligan, N. Hawkins, and G. Garriga. 2004. Caenorhabditis elegans WASP and Ena/VASP proteins play compensatory roles in morphogenesis and neuronal cell migration. Genetics. 167:1165-1176.

29. Sablina, A.A., G.V. Ilyinskaya, S.N. Rubtsova, L.S. Agapova, P.M. Chumakov, and B.P. Kopnin. 1998. Activation of p53-mediated cell cycle checkpoint in response to micronuclei formation. J. Cell Sci. 111:977-984.

30. Fenech, M. 2006. Cytokinesis-block micronucleus assay evolves into a "cytome" assay of chromosomal instability, mitotic dysfunction and cell death. Mutat. Res. 600:58-66.

31. Bubb, M.R., A.M. Senderowicz, E.A. Sausville, K.L. Duncan, and E.D. Korn. 1994. Jasplakinolide, a cytotoxic natural product, induces actin polymerization and competitively inhibits the binding of phalloidin to F-actin. J. Biol. Chem. 269:14869-14871.

32. Bubb, M.R., I. Spector, B.B. Beyer, and K.M. Fosen. 2000. Effects of jasplakinolide on the kinetics of actin polymerization. An explanation for certain in vivo observations. J. Biol. Chem. 275:5163-5170.
33. Strome, S. 1986. Fluorescence visualization of the distribution of microfilaments in gonads and early embryos of the nematode Caenorhabditis elegans. J. Cell Biol. 103:2241-2252.

34. Ancliff, P.J. 2003. Congenital neutropenia. Blood Rev. 17:209-216.

35. Kollner, I., B. Sodeik, S. Schreek, H. Heyn, N. von Neuhoff, M. Germeshausen, C. Zeidler, M. Kruger, B. Schlegelberger, K. Welte, and C. Beger. 2006. Mutations in neutrophil elastase causing congenital neutropenia lead to cytoplasmic protein accumulation and induction of the unfolded protein response. Blood. 108:493-500.

36. Klein, C., M. Grudzien, G. Appaswamy, M. Germeshausen, I. Sandrock, A.A. Schaffer, C. Rathinam, K. Boztug, B. Schwinzer, N. Rezaei, et al. 2007. HAX1 deficiency causes autosomal recessive severe congenital neutropenia (Kostmann disease). Nat. Genet. 39:86-92.

37. Uetake, Y., and G. Sluder. 2004. Cell cycle progression after cleavage failure: mammalian somatic cells do not possess a "tetraploidy checkpoint". J. Cell Biol. 165:609-615.

38. Sablina, A.A., L.S. Agapova, P.M. Chumakov, and B.P. Kopnin. 1999. p53 does not control the spindle assembly cell cycle checkpoint but mediates G1 arrest in response to disruption of microtubule system. Cell Biol. Int. 23:323-334.

39. Lohez, O.D., C. Reynaud, F. Borel, P.R. Andreassen, and R.L. Margolis. 2003. Arrest of mammalian fibroblasts in G1 in response to actin inhibition is dependent on retinoblastoma pocket proteins but not on p53. J. Cell Biol. 161:67-77.

40. Vogel, C., A. Kienitz, I. Hofmann, R. Muller, and H. Bastians. 2004. Crosstalk of the mitotic spindle assembly checkpoint with p53 to prevent polyploidy. Oncogene. 23:6845-6853.

41. Meraldi, P., R. Honda, and E.A. Nigg. 2004. Aurora kinases link chromosome segregation and cell division to cancer susceptibility. Curr. Opin. Genet. Dev. 14:29-36.

42. Harrington, E.A., D. Bebbington, J. Moore, R.K. Rasmussen, A.O Jose-Adeogun, T. Nakayama, J.A. Graham, C. Demur, T. Hercend, A. Diu-Hercend, et al. 2004. VX-680, a potent and selective smallmolecule inhibitor of the Aurora kinases, suppresses tumor growth in vivo. Nat. Med. 10:262-267.

43. Gachet, Y., S. Tournier, J.B. Millar, and J.S. Hyams. 2001. A MAP kinase-dependent actin checkpoint ensures proper spindle orientation in fission yeast. Nature. 412:352-355.

44. Muris, D.F., T. Verschoor, N. Divecha, and R.J. Michalides. 2002. Constitutive active GTPases Rac and Cdc42 are associated with endoreplication in PAE cells. Eur. J. Cancer. 38:1775-1782.

45. Demaison, C., K. Parsley, G. Brouns, M. Scherr, K. Battmer, C. Kinnon, M. Grez, and A.J. Thrasher. 2002. High-level transduction and gene expression in hematopoietic repopulating cells using a human immunodeficiency [correction of imunodeficiency] virus type 1-based lentiviral vector containing an internal spleen focus forming virus promoter. Hum. Gene Ther. 13:803-813

46. Nicoletti, I., G. Migliorati, M.C. Pagliacci, F. Grignani, and C. Riccardi. 1991. A rapid and simple method for measuring thymocyte apoptosis by propidium iodide staining and flow cytometry. J. Immunol. Methods. 139:271-279

47. Oceguera-Yanez, F., K. Kimura, S. Yasuda, C. Higashida, T. Kitamura, Y. Hiraoka, T. Haraguchi, and S. Narumiya. 2005. Ect2 and MgcRacGAP regulate the activation and function of $\mathrm{Cdc} 42$ in mitosis. J. Cell Biol. 168:221-232.

48. Rabut, G., and J. Ellenberg. 2004. Automatic real-time three-dimensional cell tracking by fluorescence microscopy. J. Microsc. 216:131-137. 